\title{
A 3 W High-Voltage Single-Chip Green Light-Emitting Diode with Multiple-Cells Network
}

\author{
W. Wang, ${ }^{1,2}$ Y. Cai, ${ }^{2}$ Y. B. Zhang, ${ }^{2}$ H. J. Huang, ${ }^{2}$ W. Huang, ${ }^{3}$ H. O. Li, ${ }^{3}$ \\ B. S. Zhang, ${ }^{2}$ and H.X. Wang ${ }^{1}$ \\ ${ }^{1}$ Key Laboratory for Physical Electronics and Devices of the Ministry of Education, Xian Jiaotong University, Xian, \\ Shaanxi 710049, China \\ ${ }^{2}$ Key Laboratory of Nanodevices and Applications, Suzhou Institute of Nano-Tech and Nano-Bionics, Chinese Academy of Sciences, \\ Suzhou, Jiangsu 215123, China \\ ${ }^{3}$ WuXi Jingkai Technology Co., Ltd., Wuxi, Jiangsu 214061, China
}

Correspondence should be addressed to Y. Cai; ycai2008@sinano.ac.cn

Received 6 March 2015; Revised 27 April 2015; Accepted 27 April 2015

Academic Editor: Meiyong Liao

Copyright (C) 2015 W. Wang et al. This is an open access article distributed under the Creative Commons Attribution License, which permits unrestricted use, distribution, and reproduction in any medium, provided the original work is properly cited.

A parallel and series network structure was introduced into the design of the high-voltage single-chip (HV-SC) light-emitting diode to inhibit the effect of current crowding and to improve the yield. Using such a design, a $6.6 \times 5 \mathrm{~mm}^{2}$ large area LED chip of 24 parallel stages was demonstrated with $3 \mathrm{~W}$ light output power (LOP) at the current of $500 \mathrm{~mA}$. The forward voltage was measured to be $83 \mathrm{~V}$ with the same current injection, corresponding to $3.5 \mathrm{~V}$ for a single stage. The LED chip's average thermal resistance was identified to be $0.28 \mathrm{~K} / \mathrm{W}$ by using infrared thermography analysis.

\section{Introduction}

The compound semiconductor $\mathrm{GaN}$ is a promising material for blue-green light-emitting diodes (LEDs) and construction of white light sources. LEDs have numerous applications $[1,2]$; thus they have attracted considerable attention. Commercialized LEDs are now being used in many areas such as general illumination [3], signaling, and back lighting in liquid crystal displays [4]. However, high-power LEDs used in projector, fluorescence microscopy, and general lighting still require much of research effort.

There are several methods proposed to improve LED's performance based on two aspects. One is to enhance the quantum efficiency of $\mathrm{GaN}$ materials such as insertion of an AlN interlayer [5], low temperature GaN [6] for stress reduction, patterned sapphire substrates (PSSs) [7], epitaxial lateral overgrowth (ELOG) [8], and some other modified ELOG techniques [9]. Another is to improve the LED's efficiency droop, such as suppression of Auger recombination [10], polarization matched $\mathrm{GaN}$ [11], and insertion of electron blocking layer (EBL) [12]. As a common sense, the most direct approach to improve the optical power is to enlarge the chip's size. Alternating-current light-emitting diodes (AC-LEDs) [13] and high-voltage LEDs (HV-LEDs) [14] with serial connection structure were demonstrated to overcome low light extraction efficiency (LEE), poor current spreading, and serious luminous efficiency droop. However, AC-LEDs waste half of the active area and HV-LEDs are out of work if one of the LED cells becomes open circuit. Furthermore, an even larger area LED needs a special design to make sure that the LED chip has a high product yield. In particular, with the design in this work, the cost of the package for traditional HVLEDs and AC-LEDs used as module can be reduced. And it will lead to a more compact lighting system for applications.

Recently, we fabricated a high-voltage single-chip large area $\left(6.6 \times 5 \mathrm{~mm}^{2}\right)$ green LED with $3 \mathrm{~W}$ light output power. In this paper, the electrical and optical properties of this green LED are presented. The 2-dimensional junction temperature distribution was also analyzed.

\section{LED Chip Design and Fabrication}

A special design of parallel and series network with multiple small LED cells was presented to improve the yield and 


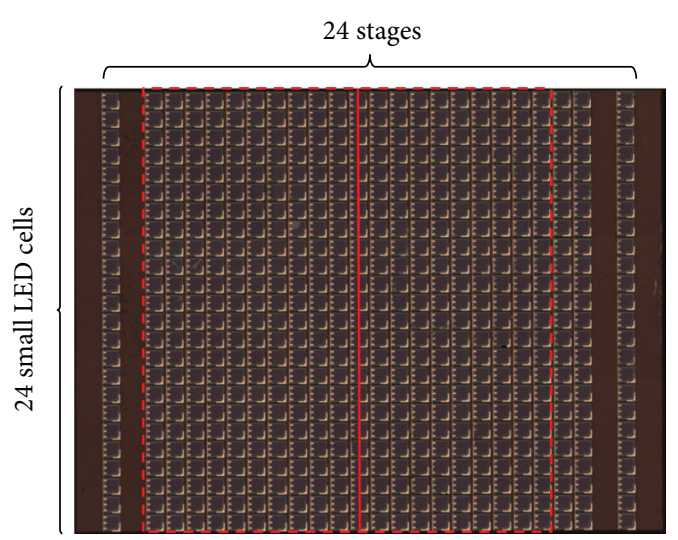

Figure 1: The micro photo of a HV-SC LED chip with 24 parallel stages $\left(6.6 \times 5 \mathrm{~mm}^{2}\right)$.

overcome the current crowding effect. As shown in Figure 1, the HV-SC LED chip consists of 24 parallel stages connected in series, and each stage has 24 small LED cells in parallel connection. The size of a small LED cell is $200 \times 200 \mu \mathrm{m}^{2}$.

In this work, the InGaN/GaN LED wafer was acquired commercially from Xiangneng Hualei Optoelectronic Co. Ltd. with a wavelength of $520 \mathrm{~nm}$. After the cleaning of GaN epiwafer, a $\mathrm{SiO}_{2}$ hard mask layer for isolation region etching and mesa etching was deposited on the p-type GaN layer using plasma-enhanced chemical vapor deposition (PECVD, Oxford System 100). After the $\mathrm{SiO}_{2}$ mask was patterned, the isolation etching and mesa etching were carried out, respectively, by an inductively coupled plasma (ICP) system (Oxford ICP 180). A sidewall slope of approximately $45^{\circ}$ was selected to form on the GaN epiwafer for smooth coverage of interconnect metal. A dielectric layer of $200 \mathrm{~nm} \mathrm{SiO}_{2}$ was then deposited, and the RIE dry etching was carried out to open the dielectric window. After that, an indium tin oxide (ITO) film was deposited and wet-etched to form p-contact. A $\mathrm{Ti} / \mathrm{Al} / \mathrm{Ni} / \mathrm{Au}$ multilayer was subsequently evaporated on the epiwafer to form n-contact and interconnection metals. An Al back reflector was sputtered on the back of the sapphire substrate after polishing down to $150 \mu \mathrm{m}$. The chip was mounted on an $\mathrm{Al}$ based heat sink by the soldering, and a hemispherical borosilicate glass lens with $13 \mathrm{~mm}$ diameters was covered on the chip by KER2500 AB silicone.

\section{Results and Discussion}

Figure 2 shows the typical $I-V$ characteristics of the fabricated HV-SC LED evaluated by Keithley 4200. The measured forward voltage is $83 \mathrm{~V}$, corresponding to $3.5 \mathrm{~V}$ for each parallel stage at $500 \mathrm{~mA}$. A reverse leakage current of $8 \mathrm{nA}$ is measured at $-120 \mathrm{~V}$, confirming the advantage of suppressing reverse leakage current in the series connected HV LED chips compared with the single parallel stage, whose reverse current is several microamperes at $-5 \mathrm{~V}$.

The optical properties of a HV-SC LED were measured by Everfine HAAS 2000 spectrometer with a large integrating sphere of $1.5 \mathrm{~m}$ inner diameter. A fan of $\sim 1 \mathrm{~W}$ was set

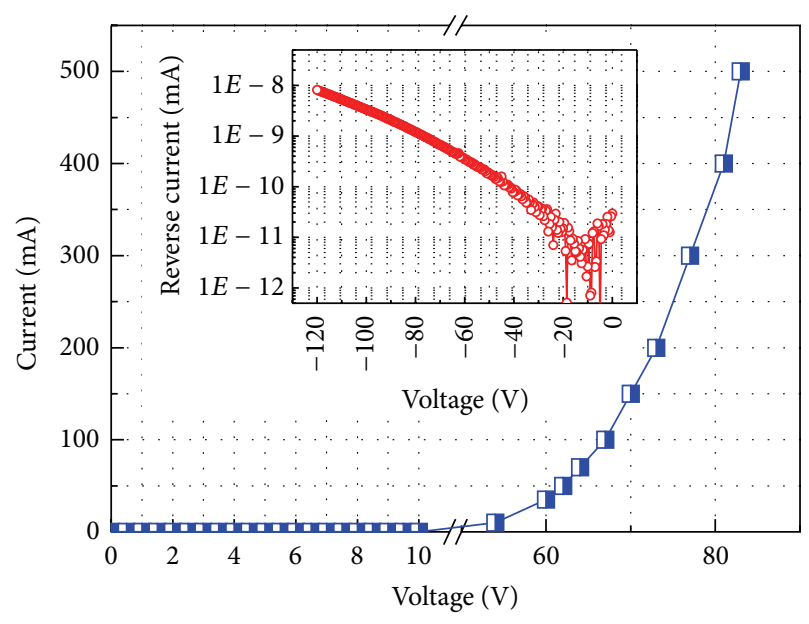

Figure 2: Typical $I-V$ characteristics of a HV-SC LED and the reverse current in the inset.

at the back of the device for cooling. Figure 3 presents a luminous photo of the LED driven at $10 \mathrm{~mA}$, and the LOP and external quantum efficiency (EQE) varying with injection current. As shown in Figure 3(b), the green light output power was measured to be $3 \mathrm{~W}$ at $500 \mathrm{~mA}$, and the EQE was calculated to be $12.6 \%$, which is $44.2 \%$ lower than its peak value of $22.6 \%$ at $35 \mathrm{~mA}$. The light output power provided by the wafer suppliers was about $60 \mathrm{~mW}$ at the current of $350 \mathrm{~mA}$ for the chip size of $30 \times 30 \mathrm{mil}^{2}$. The $9 \% \mathrm{EQE}$ of the HVSC LED agreed with the reference value of $8.9 \%$ calculated by the parameters for the wafers, at the same current density, without lens.

Infrared thermography analysis using QFI InfraScope II was also carried out to display the junction temperature distribution and calculate the average junction temperature. The HV-SC LED chip was mounted on a thermostatic plate with a constant temperature of $23^{\circ} \mathrm{C}$ by thermal conductive silica gel.

Figure 4 shows the 2D junction temperature distribution on the chip area highlighted by the red dashed line, as indicated in Figure 1. Due to the heat crowding effect, the junction temperature at the center is higher than that at the periphery. The temperature profile along the red line from bottom to top in Figure 1 is plotted in Figure 5. The temperature at the center $\left(T_{c}\right)$ is about $36.8^{\circ} \mathrm{C}$, while the temperature at the edge $\left(T_{e}\right)$ is about $30.7^{\circ} \mathrm{C}$.

To evaluate the heat dissipation capacity of this large area LED chip, the average thermal resistance $\left(R_{J \text { Average }}\right)$ and the peak thermal resistance $\left(R_{J-P e a k}\right)$ should be considered. They can be calculated by the following equation (see [15]):

$$
R_{J X}=\frac{T_{J}-T_{a}}{P_{H}}
$$

where $R_{J X}, T_{J}, T_{a}$, and $P_{H}$ are the thermal resistance, the junction temperature, the ambient temperature, and the heat dissipation power, respectively. $T_{J}$ was $33.8^{\circ} \mathrm{C}$ and $36.8^{\circ} \mathrm{C}$ for $R_{J-\text { Average }}$ and $R_{J_{-} \text {Peak }}$, respectively. So, $R_{J \text {-Average }}$ and $R_{J-\text { Peak }}$ were evaluated to be $0.28 \mathrm{~K} / \mathrm{W}$ and $0.36 \mathrm{~K} / \mathrm{W}$, corresponding 


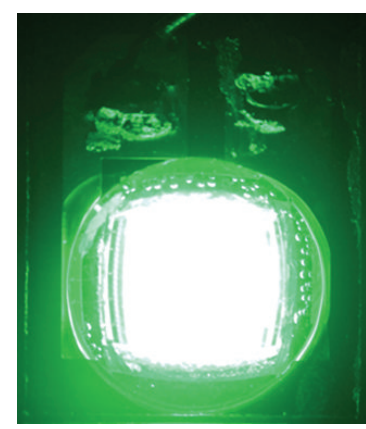

(a)

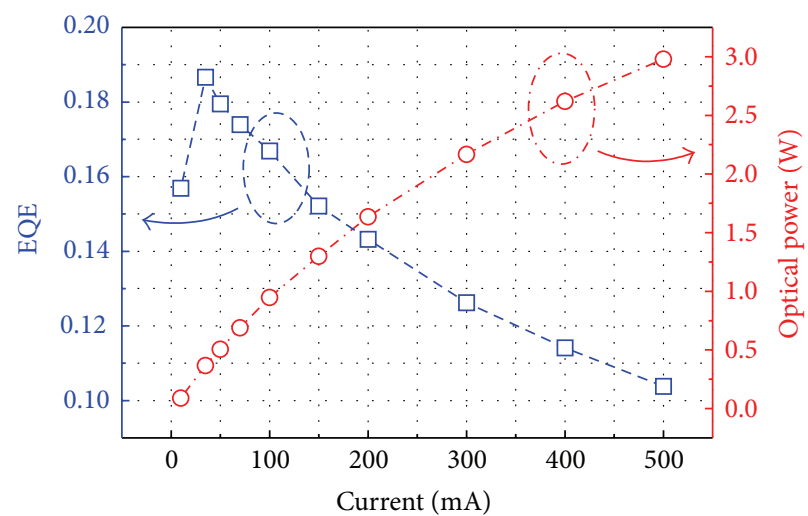

(b)

FIGURE 3: (a) The luminous photo of a HV-SC LED with optical lens driven at $10 \mathrm{~mA}$ and (b) the LOP and external quantum efficiency (EQE) of the HV-SC LED.

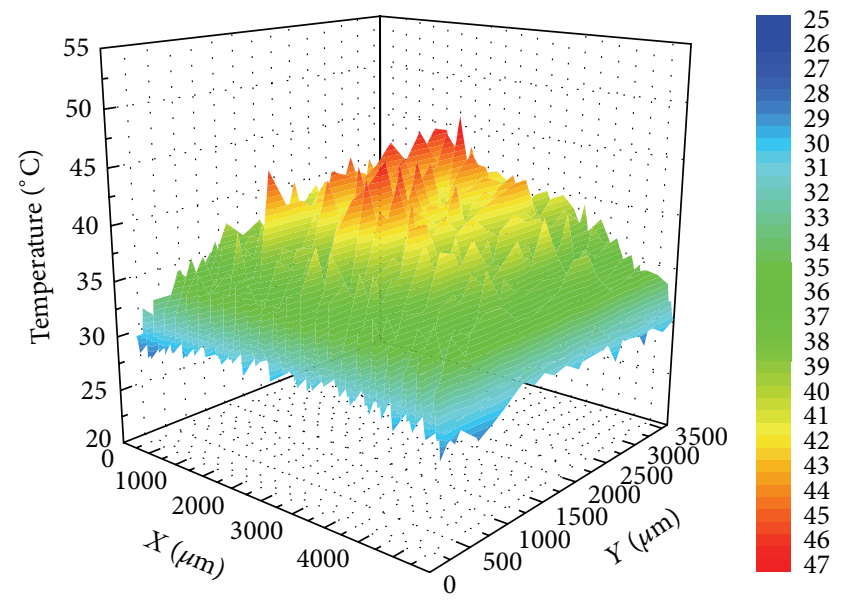

FIGURE 4: 2D junction temperature distribution in the red dashed line highlighted area in Figure 1.

to $R_{J \_ \text {Peak }} / R_{J_{-A v e r a g e}}$ ratio of 1.29 , showing the extent of the heat crowding effect.

For the heat flow through the plate with the constant cross-sectional area, the average thermal resistance can also be calculated by (2), according to the definition

$$
R_{T}=\frac{1}{\kappa} \cdot \frac{L}{A},
$$

where $R_{T}$ is the average thermal resistance, $\kappa$ is the thermal conductivity, $L$ is the chip's thickness, and $A$ is the area. The average thermal resistance of the HV-SC chip was calculated to be $0.26 \mathrm{~K} / \mathrm{W}, 0.02 \mathrm{~K} / \mathrm{W}$ higher than the calculated result because of the heat crowding effect and the additional thermal resistances of the silica gel and the heat sink.

It is well known that the forward current density of an LED strongly depends on the junction temperature, as shown in the following equation (see [16]):

$$
J \propto T^{3+\gamma / 2} \exp \left(\frac{q\left(V-I R_{s}-V_{i}\right)}{n_{\text {ideal }} k T}\right) .
$$

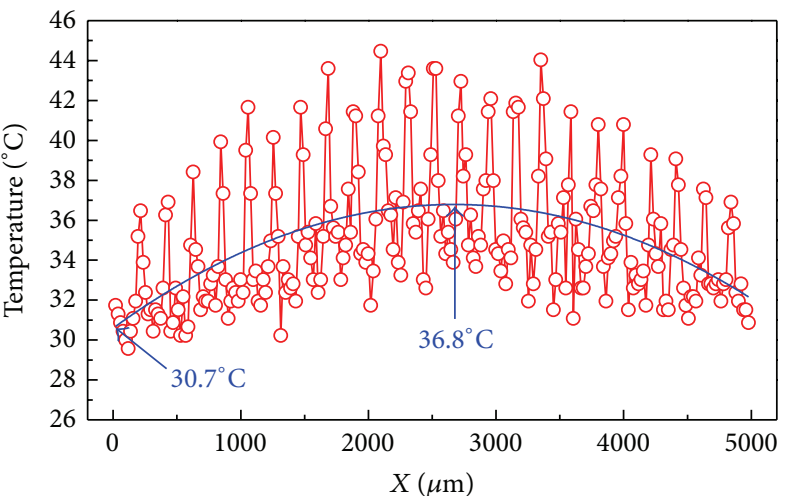

FIGURE 5: The chip's temperature and fitting curve along the red line from bottom to top in Figure 1.

So the junction temperature spatial distribution leads to the forward current density spatial distribution. For a junction temperature distribution as shown in Figure 5, the current density at the center of the chip $\left(J_{c}\right)$ should be higher than that at the edge $\left(J_{e}\right)$, implying a current crowding effect. It should be noted that the small LED cells along the red line, as shown in Figure 1, are connected in parallel. The ratio of $J_{c} / J_{e}$ represents the extent of the current crowding. In practice, when this ratio $\leq e$ (Euler's number), the device is considered appropriately designed [3].

According to (3), the ratio of $J_{c} / J_{e}$ can be expressed as

$$
\frac{J_{c}}{J_{e}}=\left(\frac{T_{c}}{T_{e}}\right)^{3+\gamma / 2} \frac{\exp \left(q\left(V-I_{c} R_{s}-V_{i}\right) / n_{\text {ideal }} k T_{c}\right)}{\exp \left(q\left(V-I_{e} R_{s}-V_{i}\right) / n_{\text {ideal }} k T_{e}\right)},
$$

where $T_{c}$ and $T_{e}$ were found to be $36.8^{\circ} \mathrm{C}$ and $30.7^{\circ} \mathrm{C}$, respectively, in Figure 5. $V_{i}$ is estimated to be $3.4 \mathrm{~V}$ in $\mathrm{In}_{0.2} \mathrm{Ga}_{0.8} \mathrm{~N} / \mathrm{GaN} \mathrm{QWs}$ [17] and $\gamma$ is regarded as 2 to evaluate the maximum valve of the $J_{c} / J_{e}$ ratio. As a result, the ratio of $J_{c} / J_{e}$ was estimated less than 1.029, which is much less than $e$ $(\sim 2.72)$, indicating no obvious current crowding effect, thus validating the effectiveness of the chip design. 


\section{Conclusion}

In this study, we introduced a parallel and series network structure into the design of a large area high-power LED chip, which suppresses the effect of current crowding and enhances the fabrication yield of the LED chip. We also successfully demonstrated a $6.6 \times 5 \mathrm{~mm}^{2}$ large area HV-SC green LED array of 24 parallel stages. With a driven current at $500 \mathrm{~mA}$, the forward voltage was measured to be $83 \mathrm{~V}, 3.5 \mathrm{~V}$ for each stage, and $3 \mathrm{~W}$ light output power with an EQE of $12.6 \%$. Based on the infrared thermography analysis, the measured average thermal resistance was $0.28 \mathrm{~K} / \mathrm{W}$ and the self-heating induced current crowding is negligible. Such a high-power, high-voltage LED device has a great potential in RGB solid state lighting.

\section{Conflict of Interests}

The authors declare that there is no conflict of interests regarding the publication of this paper.

\section{Acknowledgments}

The authors would like to thank the National Natural Science Foundation of China (no. 10990102) and Jiangsu Natural Science Foundation (BK2011173) for partially financially supporting this research.

\section{References}

[1] J. J. Wierer Jr., A. David, and M. M. Megens, "III-nitride photonic-crystal light-emitting diodes with high extraction efficiency," Nature Photonics, vol. 3, no. 3, pp. 163-169, 2009.

[2] S. Nakamura, T. Mukai, and M. Senoh, "Candela-class highbrightness InGaN/AlGaN double-heterostructure blue-lightemitting diodes," Applied Physics Letters, vol. 64, no. 13, pp. 1687-1689, 1994.

[3] E. F. Schubert, Light-Emitting Diodes, Cambridge University Press, New York, NY, USA, 2nd edition, 2006.

[4] Y. Narukawa, I. Niki, K. Izuno, M. Yamada, Y. Murazaki, and T. Mukai, "Phosphor-conversion white light emitting diode using InGaN near-ultraviolet chip," Japanese Journal of Applied Physics, vol. 41, no. 4, pp. L371-L373, 2002.

[5] A. Dadgar, M. Poschenrieder, J. Bläsing, K. Fehse, A. Diez, and A. Krost, "Thick, crack-free blue light-emitting diodes on $\mathrm{Si}(111)$ using low-temperature AlN interlayers and in situ $\mathrm{Si}_{x} \mathrm{~N}_{y}$ masking," Applied Physics Letters, vol. 80, no. 20, pp. 3670-3672, 2002.

[6] Y. L. Tsai and J. R. Gong, "Improvement in optical properties and surface morphologies of GaN films using low-temperature GaN interlayers," Journal of Crystal Growth, vol. 263, no. 1-4, pp. 176-180, 2004.

[7] S. J. Chang, Y. C. Lin, Y. K. Su et al., "Nitride-based LEDs fabricated on patterned sapphire substrates," Solid-State Electronics, vol. 47, no. 9, pp. 1539-1542, 2003.

[8] P. Vennéguès, B. Beaumont, V. Bousquet, M. Vaille, and P. Gibart, "Reduction mechanisms for defect densities in GaN using one- or two-step epitaxial lateral overgrowth methods," Journal of Applied Physics, vol. 87, no. 9, pp. 4175-4181, 2000.
[9] D. W. Kim, C. H. Jeong, K. N. Kim et al., "High rate sapphire $\left(\mathrm{Al}_{2} \mathrm{O}_{3}\right)$ etching in inductively coupled plasmas using axial external magnetic field," Thin Solid Films, vol. 435, no. 1-2, pp. 242-246, 2003.

[10] K. T. Delaney, P. Rinke, and C. G. van de Walle, "Auger recombination rates in nitrides from first principles," Applied Physics Letters, vol. 94, no. 19, pp. 191109-191112, 2009.

[11] M. H. Kim, W. Lee, D. Zhu et al., "Partial polarization matching in GaInN-based multiple quantum well blue LEDs using ternary GaInN barriers for a reduced efficiency droop," IEEE Journal on Selected Topics in Quantum Electronics, vol. 15, no. 4, pp. 1122-1127, 2009.

[12] Y. Y. Zhang, X. L. Zhu, Y. A. Yin, and J. Ma, "Performance enhancement of near-UV Light-emitting diodes with an InAlN/GaN superlattice electron-blocking layer," IEEE Electron Device Letters, vol. 33, pp. 994-996, 2012.

[13] J. P. Ao, H. Sato, T. Mizobuch et al., "Monolithic blue LED series arrays for high-voltage AC operation," Physica Status Solidi (A), vol. 194, pp. 376-379, 2002.

[14] R.-H. Horng, K.-C. Shen, Y.-W. Kuo, and D.-S. Wuu, "Effects of cell distance on the performance of GaN high-voltage light emitting diodes," ECS Solid State Letters, vol. 1, no. 5, pp. R21R23, 2012.

[15] S. Murata and H. Nakada, "Adding a heat bypass improves the thermal characteristics of a $50 \mu \mathrm{m}$ spaced 8-beam laser diode array," Journal of Applied Physics, vol. 72, no. 6, pp. 2514-2516, 1992.

[16] E. K. Liu, B. S. Zhu, and J. S. Luo, The Physics of Semiconductors, Publishing House of Electronics Industry, Beijing, China, 7th edition, 2014.

[17] F. Chen and A. N. Cartwright, "Out-of-well carrier screening in a strained $\operatorname{In}_{x} \mathrm{Ga}_{1-x} \mathrm{~N} / \mathrm{GaN}$ multiple quantum well structure," Physical Review B, vol. 68, Article ID 233304, 2003. 

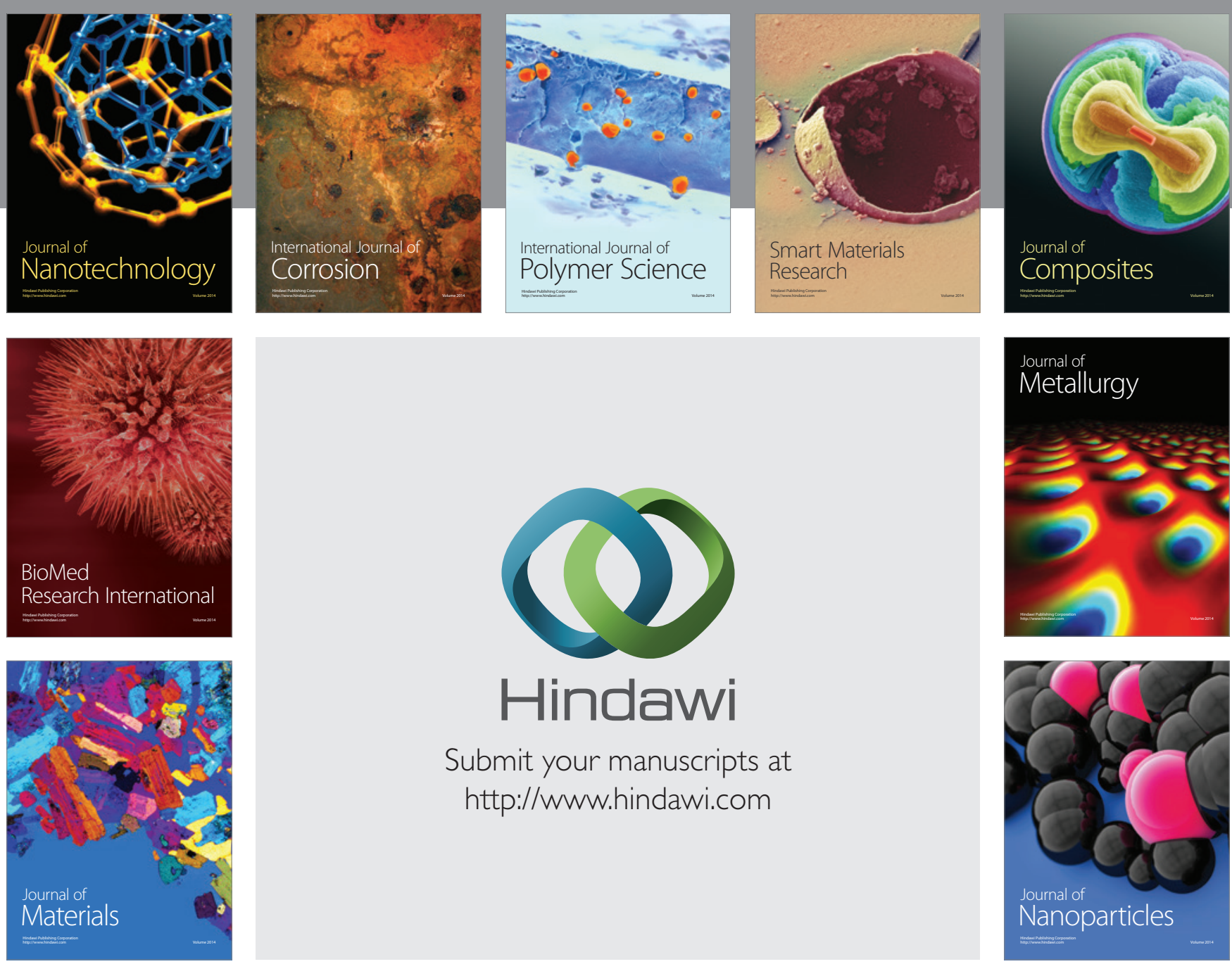

Submit your manuscripts at http://www.hindawi.com
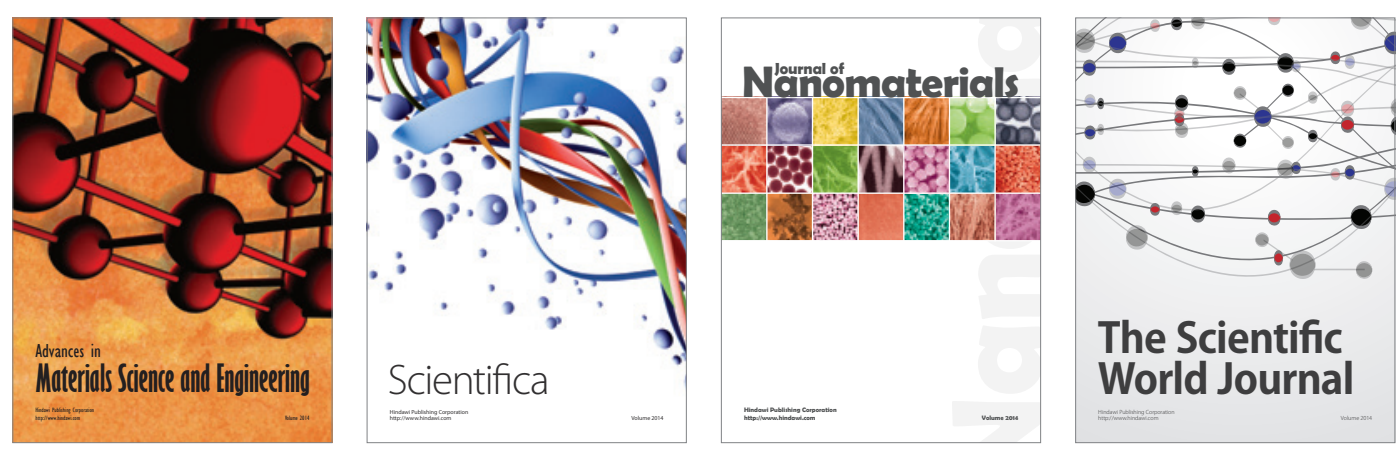

\section{The Scientific World Journal}
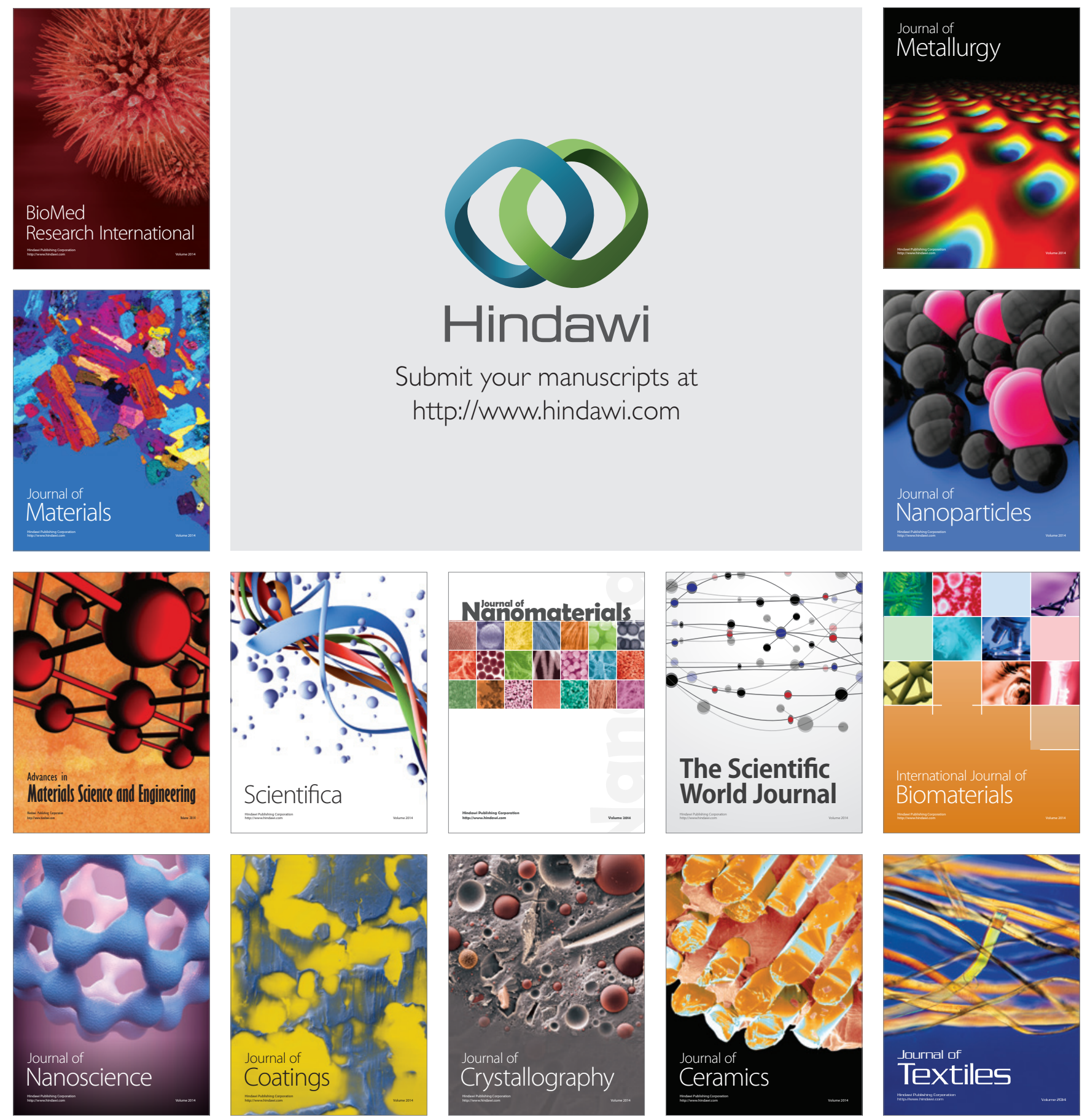